\title{
The Effects of Vibration Stimuli Applied to the Shoulder Joint on the Activity of the Muscles Around the Shoulder Joint
}

\author{
Su-kyoung Lee, PT, $\mathrm{PhD}^{1)}$ \\ 1) Department of Physical Therapy, Gimhae College: 77-9 San, Sambang-dong, Gimae, \\ Gyeongsangnam-do, Republic of Korea
}

\begin{abstract}
Purpose] The present study compared the muscle activity of the upper trapezius with those of the serratus anterior and the lower trapezius when slings, unstable surfaces, were laterally vibrated, to examine the effects of vibration during sling exercises on shoulder stabilization muscles. [Methods] The subjects performed push-up exercises on a sling and maintained isometric contraction in the final stage, while vibration was manually administered to the rope of the sling during the isometric-contraction stage. Vibration within a range of $10 \mathrm{~cm}$ was delivered for five seconds at a frequency of $1 \mathrm{~Hz}$ in time with a metronome. Vibrations were applied for five seconds at $3 \mathrm{~Hz}$ and $3.5 \mathrm{~Hz}$, respectively. [Results] The serratus anterior showed a significant differences between isometric contraction with vibration of $3 \mathrm{~Hz}$ and isometric contraction with vibration of $3.5 \mathrm{~Hz}$. [Conclusion] The upper trapezius and the lower trapezius showed prominent changes in muscle activity at $3.5 \mathrm{~Hz}$, and the serratus anterior showed prominent changes in muscle activity at $3 \mathrm{~Hz}$ and $3.5 \mathrm{~Hz}$. Therefore, as vibration frequency increased, making the load-bearing surface more unstable, the recruitment of the upper trapezius, the lower trapezius, and the serratus anterior increased. To perform exercises that selectively strengthen the serratus anterior, the exercises should be performed at a vibration frequency of $3 \mathrm{~Hz}$.
\end{abstract}

Key words: Vibration, Shoulder joint, Muscle activity

(This article was submitted Apr. 19, 2013, and was accepted Jun. 7, 2013)

\section{INTRODUCTION}

The shoulder joint's normal functions and its stability are important in daily living. The shoulder joint is a joint that relies on interactions and balance among multiple joints ${ }^{1,2)}$ The shoulder joint relies more on muscles than on bones or ligaments to support the shoulder and maintain the stability of the shoulder ${ }^{3)}$. Stabilization relates to the human ability to consciously or subconsciously control large or small movements occurring in the joints ${ }^{4}$. The movements of the shoulder bone and the humeral bone are controlled by the coupling force of two muscles: the rotator-cuff muscle and the elevator muscle of the scapular. If this coupling force collapses, the muscle-coordination activity does not occur and the rotator cuff is compressed ${ }^{5)}$. In this case, the humeral head only partially maintains contact with the articular fovea, leading to many pathologic conditions, such as shoulder instability ${ }^{3,6)}$. The activity of the scapular stabilizer muscles is important in counteracting the instability that occurs due to the aforementioned structural problems. The scapular stabilizer muscles include the serratus anterior,

Corresponding author. Su-kyoung Lee (e-mail: holeintwo@ naver.com)

C2013 The Society of Physical Therapy Science

This is an open-access article distributed under the terms of the Creative Commons Attribution Non-Commercial No Derivatives (by-ncnd) License $<$ http://creativecommons.org/licenses/by-nc-nd/3.0/>. the upper trapezius, and the lower trapezius ${ }^{7)}$. In particular, the activity of the serratus anterior muscle is very important for scapular movements and control $^{8,9)}$. Extensive electromyography (EMG) studies of the stabilizer muscles that contribute to shoulder stabilization have been carried out. The muscle activity of the serratus anterior and that of the upper trapezius have been shown to be imbalanced in subacromial-impingement syndrome, subacromial bursitis, rotator-cuff laceration, and rotator-cuff and biceps-brachii tendinitis ${ }^{10)}$.

Closed-chain exercises are frequently used for shoulder-joint dysfunction prevention and in rehabilitation programs ${ }^{11)}$. Closed-chain exercises are frequently used in therapeutic exercise programs to generate dynamic stability in the joints and to maintain posture, since these exercises not only improve strength and endurance, but also induce the co-contraction of many muscles through mechanical compression of articular surfaces eliciting larger proprioceptive responses by stimulating the afferent receptors around the joints ${ }^{12}$. Along with closed-chain exercises, sling exercises, which require performing exercises while hanging on swinging ropes, are one of the treatment methods that can be used to prevent injuries, since these exercises stimulate the proprioceptive senses to strengthen weakened muscles and give the necessary stimuli to maintain joint stability. Kirkesola $^{13)}$ reported that if vibrations of the rope were given during sling exercises, instability would be increased, further stimulating the proprioceptive sensory organs in the 
1408 J. Phys. Ther. Sci. Vol. 25, No. 11, 2013

Table 1. Comparison of muscle activation among the various vibration frequencies (unit: \%RVC)

\begin{tabular}{ccccc}
\hline & IC & $1 \mathrm{~Hz}$ & $3 \mathrm{~Hz}$ & $3.5 \mathrm{~Hz}$ \\
\hline UT* $^{*}$ & $0.034 \pm 0.013$ & $0.034 \pm 0.013$ & $0.035 \pm 0.013$ & $0.057 \pm 0.010$ \\
LT* $^{*}$ & $0.025 \pm 0.008$ & $0.027 \pm 0.007$ & $0.027 \pm 0.007$ & $0.053 \pm 0.009$ \\
SA* $^{*}$ & $0.051 \pm 0.012$ & $0.050 \pm 0.011$ & $0.083 \pm 0.014$ & $0.083 \pm 0.014$ \\
\hline
\end{tabular}

$* \mathrm{p}<0.05$, Mean \pm SD, IC: isometric contraction, UT: upper trapezius, LT: lower trapezius, SA: serratus anterior

joints, and incorrect neuromuscular control could be corrected, reducing muscle imbalance.

Therefore, the present study compared the muscle activity of the upper trapezius with those of the serratus anterior, and the lower trapezius when slings, unstable surfaces, were laterally vibrated, to examine the effects of vibration during sling exercises on the shoulder stabilization muscles.

\section{SUBJECTS AND METHODS}

The subjects of the present study were 15 adult men without any history of damage to the shoulder girdle or shoulder pain. The subjects' average age was $26.13 \pm 5.13$ years, their average height was $174.00 \pm 5.44 \mathrm{~cm}$, and their average weight was $73.47 \pm 13.46 \mathrm{~kg}$. The procedures of this study were harmless to the human body. All subjects read and signed a written consent form. The subjects performed push-up exercises with knee flexion. Decker et al. ${ }^{1)}$ advised that push-up exercises with knee flexion produce EMGs similar to those produced during push-up exercises with knee extension, while eliciting less force than push-up exercises with knee extension. Before EMGs were measured, the subjects performed push-up exercises with their hands placed on the floor at shoulder width, their knees placed on the floor, and their elbow joints extended. EMGs were obtained during the performance of four exercises. In the first exercise, the subject performed push-up exercises on an unstable surface (sling) and maintained isometric contraction for five seconds in a state of scapular protraction and elbow extension, in the final stage of the motion, and EMG signals from the serratus anterior, the upper trapezius muscle, and the lower trapezius muscle were collected during state of isometric contraction. In the second exercise, the subject performed push-up exercises on a sling and maintained isometric contraction in the last stage, and the rope of the sling was manually vibrated during the isometric contraction. Vibrations was given within a range of $10 \mathrm{~cm}$ for five seconds at a frequency of $1 \mathrm{~Hz}$, in time with a metronome. In the third and fourth exercises, vibrations of $3 \mathrm{~Hz}$ and $3.5 \mathrm{~Hz}$, were respectively applied.

A surface EMG-MP36 (Biopac System Inc., USA) was used to measure muscle activities during the exercises. For the measurement, electrodes were attached to the upper trapezius, the lower trapezius, and the serratus anterior. Data were processed using SPSS for Windows (Ver. 18.0), and one-way ANOVA was used to compare muscle activities among the various vibration frequencies on the unstable surface. The significance level was chosen as 0.05 .

\section{RESULTS}

The upper trapezius and the lower trapezius did not show any significant differences among isometric contraction without vibration, isometric contraction with vibration of $1 \mathrm{~Hz}$, and isometric contraction with vibration of $3 \mathrm{~Hz}$, but showed significant differences at isometric contraction with vibrations of $3.5 \mathrm{~Hz}$. The serratus anterior showed a significant differences between isometric contraction with vibration of $3 \mathrm{~Hz}$ and isometric contraction with vibration of $3.5 \mathrm{~Hz}$ (Table 1$)$.

\section{DISCUSSION}

The coupling force of the upper trapezius, the serratus anterior, and the lower trapezius is the core of scapular movements ${ }^{14)}$. If this muscle recruitment is changed, or the motions of these muscles are limited by an antagonist, the movement pattern will collapse. It has been revealed that in shoulder impingement syndrome, patients' shoulders are elevated, the muscle activity of the upper trapezius increases, and the muscle activity of the serratus anterior decreases. In particular, the serratus anterior, which is an important muscle scapular movement imbalance, has been studied by many researchers. Fatigue of the serratus anterior decreases scapular rotation and protraction, and displaces the humeral head in a forward and upward direction ${ }^{1,10,11)}$. Therefore, it may cause secondary impingement syndrome and rotatorcuff tear, decrease the range of scapular motion, or disturb the contraction timing of the serratus anterior, thereby inducing stress in the glenohumeral joint ${ }^{15}$. If abnormal scapular movements appear, due to problems in the serratus anterior, the position of the fossa would be affected, and the force and alignment involved in movements around the glenohumeral joint would eventually be affected ${ }^{16)}$. Kirkesola $^{14)}$ reported that when the rope used for sling exercises was vibrated, instability increased further stimulating the proprioceptive sensory organs in the joints, and incorrect neuromuscular control could be corrected, reducing muscle imbalance.

As the load-bearing surface becomes more unstable, the muscle activities of the serratus anterior and the lower trapezius would increase, selectively strengthening the scapular-stabilizer muscles, reducing muscle imbalance. Exercises on a sling elicit significantly higher muscle activities than exercises on a fixed surface. Therefore, exercises on a sling should simultaneously strengthen many muscles that contribute to shoulder joint stability, increasing the stability of the shoulder complex. In the present study, to 
examine the effects of diverse vibration frequencies on the upper trapezius, the lower trapezius, and the serratus anterior during exercises on a sling, an unstable surface, vibration frequencies of $1 \mathrm{~Hz}, 3 \mathrm{~Hz}$, and $3.5 \mathrm{~Hz}$ were used. In the present study, all three muscles showed gradual activity increases as the frequency of vibration increased from $1 \mathrm{~Hz}$ to $3 \mathrm{~Hz}$ and $3.5 \mathrm{~Hz}$. The upper trapezius and the lower trapezius showed significant changes in muscle activity at $3.5 \mathrm{~Hz}$, and the serratus anterior showed prominent changes in muscle activity at $3 \mathrm{~Hz}$ and $3.5 \mathrm{~Hz}$. Therefore, as the vibration frequency increased, making the bearing surface more unstable, the recruitment of the upper trapezius, the lower trapezius, and the serratus anterior increased. To perform exercises that will selectively strengthen the serratus anterior, the exercises should be performed with a vibration frequency of $3 \mathrm{~Hz}$.

\section{REFERENCES}

1) Decker MJ, Hintermeister RA, Faber KJ, et al.: Serratus anterior muscle activity during selected rehabilitation exercises. Am J Sports Med, 1999, 27: 784-791. [Medline]

2) Hess SA: Functional stability of the glenohumeral joint. Man Ther, 2000, 5: 63-71. [Medline] [CrossRef]

3) James AP, Carl D: Mechanical Shoulder Disorder: Perspectives in Functional Anatomy. Philadelphia: Elsevier Saunders, 2004, pp 91-125.

4) Magee DJ: Instability and Stabilization. Theory and Treatment, 2nd ed.
Seminar Workbook, 1999

5) Hammer WI: The Shoulder from Functional Soft Tissue Examination and Treatment by Manual Methods. Gaithersberg: Aspen, 1999, pp 35-135.

6) Magee DJ: Orthopedic Physical Assessment, 3rd ed. Philadelphia: W.B.Saunders, 1998, pp 235-240.

7) Lear LJ, Gross MT: An electromyographical analysis of the scapular stabilizing synergists during a push-up progression. J Orthop Sports Phys Ther, 1998, 28: 146-157. [Medline]

8) Dvir Z, Berme NJ: The shoulder complex in elevation of the arm: a mechanism approach. J Biomech, 1978, 11: 219-225. [Medline] [CrossRef]

9) Inman VT, Saunders JB, Abbott LC: Observations of the function of the shoulder joint. Clin Orthop Relat Res, 1996, 330: 3-12. [Medline] [CrossRef]

10) Moseley JB, Jobe FW, Pink M, et al.: EMG analysis of the scapular muscles during a shoulder rehabilition program. Am J Sports Med, 1992, 20: 128 134. [Medline] [CrossRef]

11) Ludewig PM, Hoff MS, Osowski EE, et al.: Relative balance of serratus anterior and upper trapezius muscle activity during push-up exercise. Am J Sports Med, 2004, 32: 484-493. [Medline] [CrossRef]

12) Ellenbecker TS, Davies GJ: Closed Kinetic Chain Exercise. Champaign: Human kinetics, 2001, pp 53-58.

13) Kirkesola G: Neurac-a new treatment method for long-term musculoskeletal pain. J Fysioterapeuten, 2010, 76: 16-25.

14) Sahrmann S: Diagnosis and Treatment of Movement Impairment Syndromes. Mosby, 2005.

15) Allegrucci M, Whitney SL, Irrgang JJ: Clinical implications of secondary impingement of the shoulder in freestyle swimmers. J Orthop Sports Phys Ther, 1994, 20: 307-318. [Medline]

16) Warner JJ, Micheli LJ, Arslanian LE, et al.: Scapulothoracic motion in normal shoulders and shoulders with glenohumeral instability and impingement syndrome a study using moiré topographic analysis. Clin Orthop Relat Res, 1992, 285: 191-199. [Medline] 